\title{
Variation Trends of Dust Storms in Relation to Meteorological Conditions and Anthropogenic Impacts in the Northeast Edge of the Taklimakan Desert, China
}

\author{
Aishajiang Aili' ${ }^{1}$ Nguyen Thi Kim Oanh2 ${ }^{*}$, Jilili Abuduwaili1 \\ ${ }^{1}$ State Key Laboratory of Desert and Oasis Ecology, Xinjiang Institute of Ecology and Geography, Chinese Academy of Science, \\ Urumchi, China \\ ${ }^{2}$ Environmental Engineering and Management, School of Environment, Resources and Development (SERD), Asian Institute of \\ Technology, Pathumthani, Thailand \\ Email: *kimoanh@ait.ac.th
}

How to cite this paper: Aili, A., Oanh, N.T.K. and Abuduwaili, J. (2016) Variation Trends of Dust Storms in Relation to Meteorological Conditions and Anthropogenic Impacts in the Northeast Edge of the Taklimakan Desert, China. Open Journal of Air Pollution, 5, 127-143.

http://dx.doi.org/10.4236/ojap.2016.54010

Received: August 24, 2016

Accepted: October 17, 2016

Published: October 20, 2016

Copyright $\odot 2016$ by authors and Scientific Research Publishing Inc. This work is licensed under the Creative Commons Attribution International License (CC BY 4.0).

http://creativecommons.org/licenses/by/4.0/

(c) (i) Open Access

\section{Abstract}

To reveal the multivariate relationships between man-made and meteorological factors on dust storm frequency, the LUCC data, NDVI remote sensing data and meteorological data for the period of 1983-2013 were combined with dust storm frequency data, and the possible impacts of meteorological and anthropogenic factors on dust storm frequency were analyzed by using regression analysis and PCA (Principal Component Analysis). Results show that the inter-annual dust storm frequency increased gradually. In particular, an increasing trend in recent years, after 2009, is conspicuous. The monthly frequency of dust storms shows higher values between the months of February and May, with the highest mean number of events occurring in April, which accounts for $29 \%$ of the annual dust storm frequency. The annual dust storm frequency is positively correlated with wind speed and negatively correlated with precipitation; the monthly dust storm frequency is positively correlated with wind speed, but no significant correlation can be found with precipitation. The relationship between temperature and dust storms is not simply linear, however, a certain correlation with an unremarkable statistical significance can be found between them. Human activities also affect the dynamics of dust storms indirectly via changing vegetation coverage and direct dust emissions. The multivariate analysis further confirmed the association between dust storm frequency and meteorological factors and NDVI. The high loadings of dust storm frequency, wind speed, precipitation and NDVI on a PC indicate that the increased precipitation and NDVI will decrease dust storm frequency, and increased wind speed will increase dust storm frequency. 


\section{Keywords}

Dust storm, Variation Trends, Meteorological Conditions, Anthropogenic Impact

\section{Introduction}

Dust storms are atmospheric phenomena that have been recognized as having a very wide range of environmental and climate impacts. The occurrence of this type of weather has exerted an extremely adverse effect upon the environment [1] [2]. Both human activities and natural factors can affect the dynamics of dust storms indirectly via changing vegetation coverage and direct dust emissions. Wind speed is a dynamic driver that is responsible for dust storm. In the presence of suitable land surface condition, even relatively weak winds can induce dust storm events [3] [4]. Precipitation can improve the soil moisture condition, and reduce the dust emission from surface. As the world's second largest shifting sand desert, the Taklimakan Desert and its surrounding areas have already become vulnerable regions to dust storm impacts [5]-[7]. Especially, frequent dust storms in spring cause serious environmental consequences and have negative effects for the environment and human society at the northeast edge of this desert [8].

In previous research on the Taklimakan Desert area, the entire desert was selected as a study area, and the temporal-spatial changes of dust storms were analyzed using limited meteorological observations. For example, Cheng et al. (2014) analyzed the temporal and spatial distribution characteristics of hot spots and cold spots of dust storms in Xinjiang [9]. Liu and Wei (2005) used long-term meteorological data to analyze the variation trends of dust storm frequency in southern Xinjiang and suggested that under the conditions of global warming, dust storm frequency was reduced because of reduced strong winds and increased precipitation in the previous 60 years [10]. However, there is a lack of scientific efforts on dust storm studies for the specific region of Taklimakan Desert. Therefore, this study was conducted to partly fill in this information gap. The northeast edge of the Taklimakan Desert, which has been considered an economic strategic zone and traffic center of southern Xinjiang [11], has already become an ecologically fragile region because of the frequent occurrences of dust storms. In this study, the variation trends of dust storm frequency in the period of 1983-2013 are combined with meteorological data (wind speed, temperature and precipitation), LUCC (land use/cover change) data and NDVI (Normalized Difference Vegetation Index) data. The possible impacts of meteorological conditions and human development activities on the varying trends of dust storm frequency are analyzed.

\section{Materials and Methods}

\subsection{Overall Characteristics of the Study Area}

The northeast edge of the Taklimakan Desert, including Bugur County and Korla City 
of the Xinjiang Uyghur Autonomous Region, China, was selected for analyzing the variation trends of dust storms (Figure 1). This area has a cold desert climate with clear seasonal variations in temperature. The monthly average temperature ranges from $-7.0^{\circ} \mathrm{C}$ (in January) to $26.4^{\circ} \mathrm{C}$ (in July), and the annual mean is $11.7^{\circ} \mathrm{C}$. The annual mean precipitation is only 57 millimeters. Most precipitation occurs in summer, and the annual evaporation rate is about $2800 \mathrm{~mm}$. Dust storms mainly occur in spring, and the annual frequency (1958-2008) was 17.47 times/year for suspended dust, 6.05 times/ year for blowing dust and 1.38 times/year for sand-dust storms [11]. Therefore, this area is considered to be a region with frequently occurring dust storms in Xinjiang [12] [13]. Since the discovery of oil in the Taklimakan Desert in the 1990s, this area gradually becomes an economic strategic zone and traffic center of southern Xinjiang [14]. However, due to direct contact with the desert, this region has already become an ecologically fragile region.

\subsection{Data Collection}

\subsubsection{Dust Storm Frequency and Meteorological Data}

Dust storm events in this study were classified using the criteria given by AQSIQ/NSC (2006) [15]. Accordingly, there are three types of dust events depending on the severity. The least severe type is called suspended dust weather, which refers to the suspending of dust in the air under calm or low wind conditions with the atmospheric visibility below $10 \mathrm{~km}$. The moderately severe dust weather is called blowing dust, which refers to the lower horizontal visibility, $1 \mathrm{~km}-10 \mathrm{~km}$. The most severe/strong dust weather is called a sand storm (sometimes it is also simply called a dust storm), which refers to a phenomenon when the instantaneous wind velocity is over $25 \mathrm{~m} / \mathrm{s}$ and horizontal visibility is below $1 \mathrm{~km}$ [16]. The total number of the three types of dust weather was

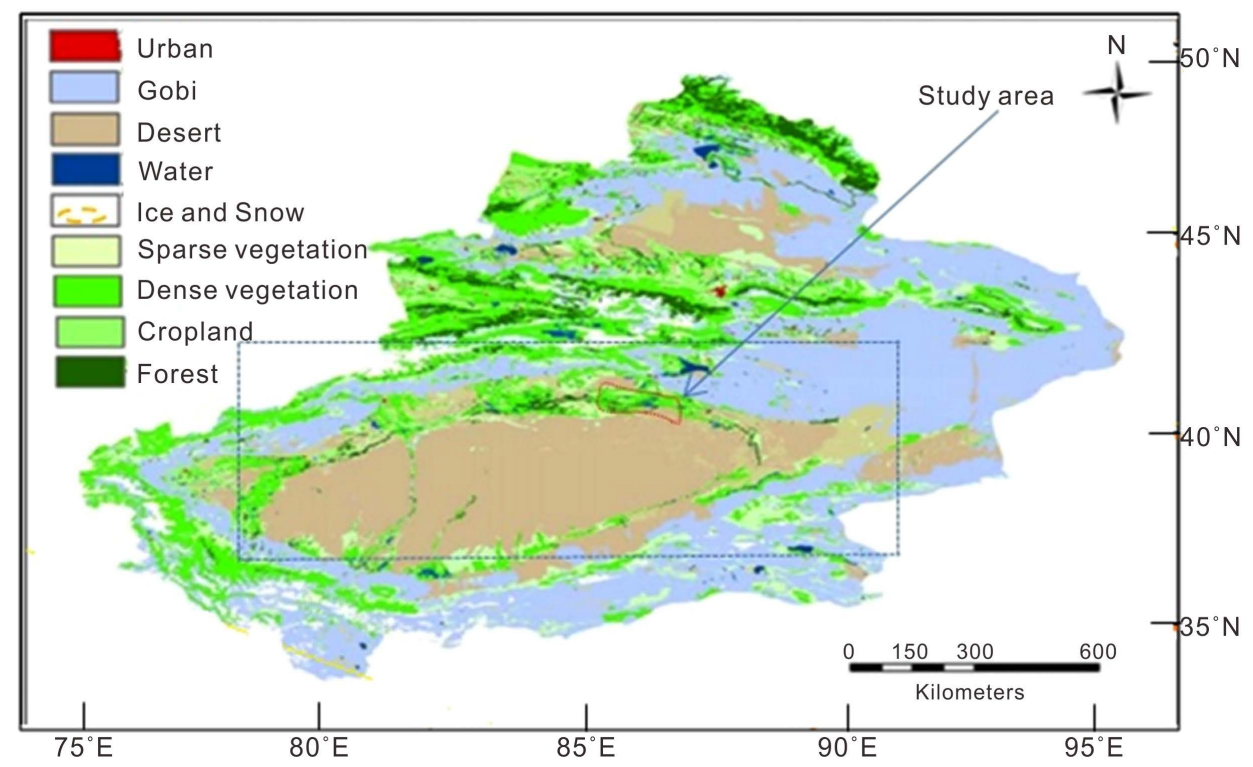

Figure 1. Location and landscape characteristics of study area (Dotted area is NDVI value calculated region). 
considered to be the annual dust storm frequency. Meteorological data, including temperature and wind speed in the period of 1983-2013 (dust storm frequency data are available from 1958), used in this study were obtained from the Bugur Meteorological Station and the China Meteorological Data Sharing Service System (http://www.cams.cma.gov.cn/), as well as from the National Oceanic and Atmospheric Administration, Air Resources Laboratory (NOAA ARL), which are available at http://www.arl.noaa.gov/ready.html.

\subsubsection{LUCC Data}

Seven types of LUCC data including agricultural land, orchard, forest, grassland, wetland, residential \& industrial land and unused land were considered in this study. Type of these lands was classified using the criteria given by National Standard Committee of China (GBT 2001-2007). Because dust storm events in the study area are associated with larger areas including the entire Taklimakan Desert and its surrounding areas, the LUCC data were collected from the entire southern Xinjiang region, including Bayingolin Mongol Autonomous district, Aksu prefecture, Kizilsu Kirgiz autonomous district, Kashgar prefecture and Hotan prefecture in the period of 1983-2013, and the relationships between LUCC and dust storm frequency were analyzed. Population data were collected from the Xinjiang statistical yearbook (1984-2014) and Internet sources.

\subsubsection{NDVI Data}

The annual mean value of NDVI in the period of 1983-2013 was obtained by using ERDAS (Earth Resources Data Analysis System) image software. In this method, the entire southern Xinjiang region $\left(36^{\circ}-42^{\circ} \mathrm{N}\right.$, and $\left.78^{\circ}-93^{\circ} \mathrm{E}\right)$ is divided into 360 grid cells of $0.5^{\circ} \times 0.5^{\circ}$ for calculating the NDVI value (dotted area in Figure 1). The remote sensing (Landsat 7) map is extracted from the Earth Explorer website

(http://earthexplorer.usgs.gov/) based on the geographical coordinates of the study area. August was selected from each year for obtaining the NDVI value because of higher vegetation coverage and clear air (fewer clouds) in this month (July was selected for 1988, 1996 and 2009, because the remote sensing image was not available or not clear in August in these years). The NDVI values in every 360 grid cells were obtained using ERDAS image software, and then they were averaged to produce the annual mean NDVI value for each year.

\subsection{Statistical Analysis}

Simple time-series analysis was conducted to check the relationships between dust storm frequency (monthly and annual) and corresponding meteorological factors and LUCC. The time-series analysis is a statistical tool that can describe the relationship between two variables based on observed data. Moreover, it can also predict the value of the dependent variable based on the value of the independent variable [17]. For example, if $y$ is a dependent variable and $x$ is an independent variable, then the linear regression model provides a prediction of $y$ from $x$ in the form of:

$$
y=\alpha+\beta x+\varepsilon
$$

where: $\alpha+\beta_{X}$ is the deterministic portion of the model and $\varepsilon$ is the random error. 
To further examine the multivariate relationships between dust storm frequency and other factors, the PCA with a Varimax rotation was applied. PCA is a statistical technique that is used to analyze the interrelationships among a large number of variables through clustering them into smaller groups (principle component), with a minimum loss of information [17]. Comparing with unrotated Empirical Orthogonal Function (EOF) and Singular Value Decomposition (SVD), the Varimax rotation criterion maximizes the sum of the variances of squared coefficients within each eigenvector, and the rotated axes remain orthogonal.

For example, let $X=\left[x_{i}\right]$ be any $k \times 1$ random vector. We now define a $k \times 1$ vector $Y$ $=\left[y_{i}\right]$, where for each $i$ the $i^{\text {th }}$ principal component of $X$ is

$$
y_{j}=\sum_{j=1}^{k} \beta_{i j} x_{j}
$$

where, $\beta_{i j}$ is a regression coefficient; since each $y_{i}$ is a linear combination of the $x_{j p} Y$ is a random vector.

A total of 13 variables, including annual dust storm frequency, three meteorological factors (annual precipitation, annual wind speed and annual mean temperature), seven types of land (agricultural land, forest, orchard, grassland, wetland, residential \& industrial land and unused land), population and annual mean NDVI value were analyzed using PCA. The NDVI value is obtained using the following formula:

$$
\mathrm{NDVI}=\left(\lambda_{\mathrm{NIR}}-\lambda_{\mathrm{RED}}\right) /\left(\lambda_{\mathrm{NIR}}+\lambda_{\mathrm{RED}}\right)
$$

where, $\lambda_{\mathrm{NIR}}$ and $\lambda_{\mathrm{RED}}$ are the reflectance in the near infrared (central wavelength of 0.63 - $0.67 \mu \mathrm{m}$ ) and red bands (central wavelength of $0.85-0.88 \mu \mathrm{m}$ ), respectively.

\section{Results and Discussions}

\subsection{Variation Trends of Dust Storms}

A total of 2526 dusty days were reported during the period of 1958-2013 with an annual mean of 45.1 dusty days. The annual frequency of the three types of dust weather from 1958 to 2013 is presented in Figure 2. The most active decades were the 1950s, 1980s and 2010s. Three peaks of dust storm frequency can be found in the long-term trend: the first peak is the period of 1959-1960 (103 days); the second peak is the period of 1981-1984, during which the mean of the annual frequency of dust storms reaches 80 days; and the third peak is in the period of 2009-2013, when the average annual frequency of dust storms reaches 72 days. The decreasing trend is more conspicuous in the period of 1962-1974 and 1982-1985 than other period.

In order to investigate the main seasons of dust storm occurrences, seasonal sub-series were used, i.e. spring (from February to April), summer (from May to July), autumn (from August to October) and winter (from November to the next January). The monthly average value of dust storm frequency in the period of 1983-2013 is presented in Figure 3 and Table 1. It can be seen from Figure 3 that the total number of dusty days in April accounts for $28.4 \%$ of each year, followed by March (21.1\%), and May (15.3\%). Collectively, $65 \%$ of the annual dust storms occur in these three months. 
During the spring season, dust storms occur most frequently each year, with an average frequency of 15.8 times/month. The lowest number of dusty days occurred in winter (from November to February).

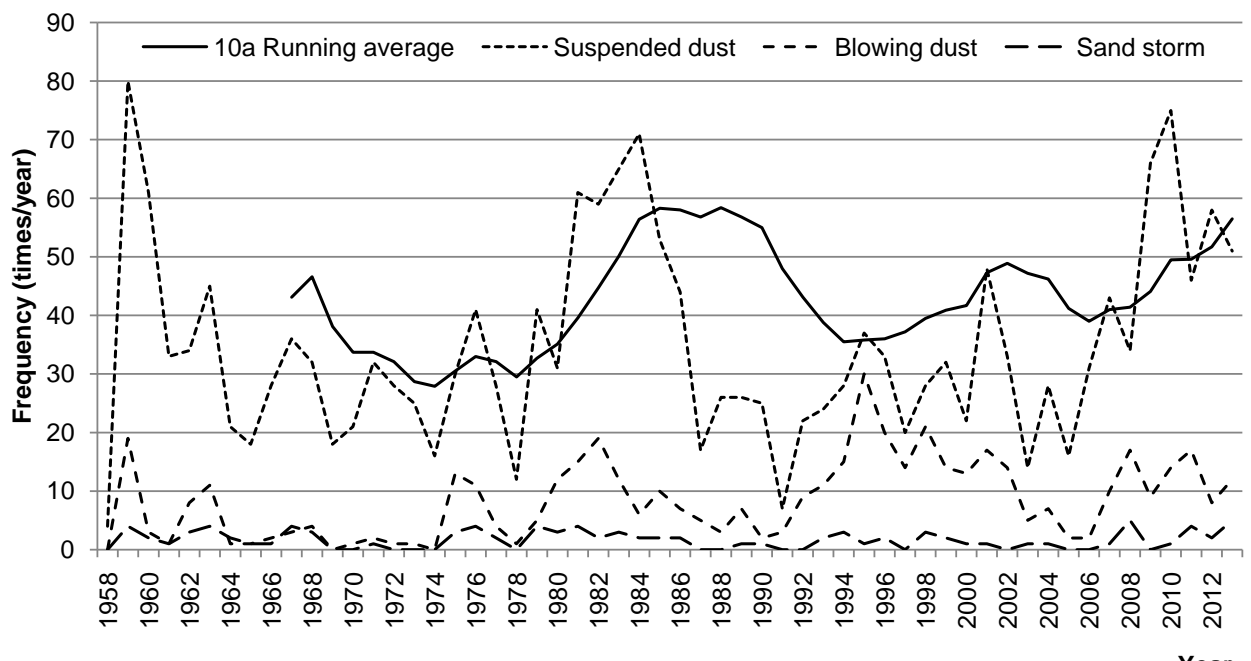

Figure 2. The interannual and 10-year running average frequency of three types of dust weather (1958-2013).

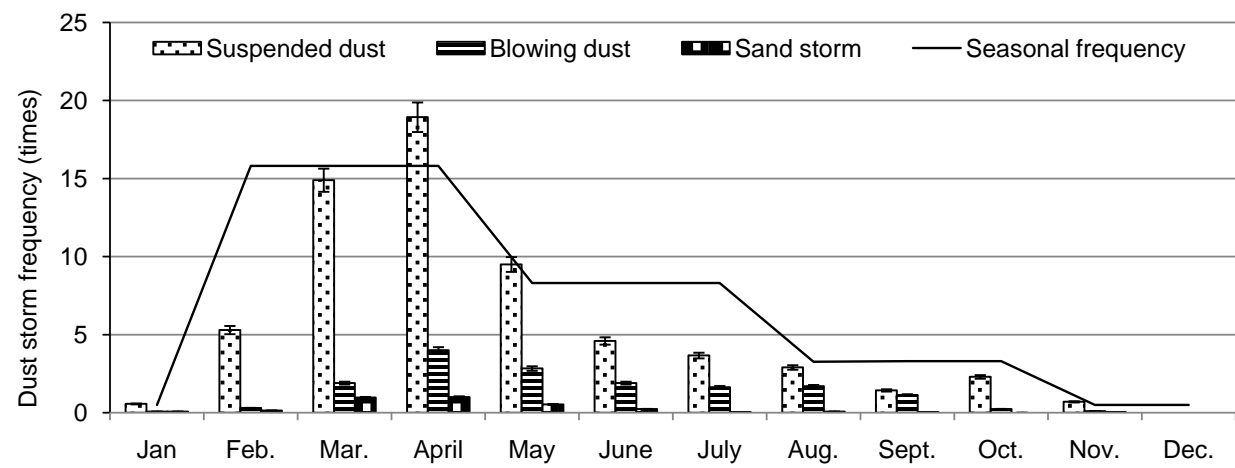

Figure 3. Monthly and seasonal average frequency of 3 types of dust storm (1983-2013).

Table 1. Monthly average frequency of dust storm and meteorological factors (1983-2013).

\begin{tabular}{ccccccccccccccc}
\hline $\begin{array}{c}\text { Meteorological } \\
\text { factors }\end{array}$ & Jan. & Feb. & Mar. & Apr. & May & June & July & Aug. & Sept. & Oct. & Nov. & Dec. \\
\hline $\begin{array}{c}\text { Temperature } \\
\left({ }^{\circ} \mathrm{C}\right)\end{array}$ & $-7.7 \pm 0.4$ & $-1.6 \pm 0.2$ & $7.58 \pm 0.4$ & $15.7 \pm 1.3$ & $21.19 \pm 1.8$ & $25.33 \pm 2.4$ & $27.03 \pm 2.2$ & $25.58 \pm 1.8$ & $20.0 \pm 1.5$ & $11.5 \pm 0.9$ & $2.34 \pm 0.3$ & $-5.52 \pm 0.4$ \\
& & & & & & & & & & & & & \\
$\begin{array}{c}\text { Precipitation } \\
(\mathrm{mm})\end{array}$ & $1.51 \pm 0.2$ & $1.8 \pm 0.2$ & $1.86 \pm 0.2$ & $2.56 \pm 0.6$ & $4.98 \pm 0.8$ & $7.25 \pm 0.7$ & $7.83 \pm 0.6$ & $5.58 \pm 0.3$ & $2.91 \pm 0.3$ & $1.81 \pm 0.1$ & $1.22 \pm 0.2$ & $1.22 \pm 0.1$ \\
$\begin{array}{c}\text { Wind speed } \\
(\mathrm{m} / \mathrm{s})\end{array}$ & $5.3 \pm 0.3$ & $4.4 \pm 0.4$ & $10.7 \pm 1.1$ & $14.8 \pm 1.4$ & $12.6 \pm 1.4$ & $6.2 \pm 1.4$ & $4.1 \pm 1.1$ & $4.7 \pm 0.4$ & $5.2 \pm 0.5$ & $4.2 \pm 0.5$ & $6.3 \pm 1.0$ & $7.8 \pm 0.5$ \\
$\begin{array}{c}\text { Dust storm } \\
\text { frequency } \\
\text { (times })\end{array}$ & $0.7 \pm 0.3$ & $5.7 \pm 0.4$ & $17.8 \pm 1.3$ & $23.9 \pm 2.6$ & $12.9 \pm 1.1$ & $6.7 \pm 0.4$ & $5.3 \pm 0.3$ & $4.7 \pm 0.2$ & $2.6 \pm 0.2$ & $2.5 \pm 0.1$ & $0.8 \pm 0.3$ & $0.5 \pm 0.2$
\end{tabular}




\subsection{Relationship between Dust Storm Frequency and Meteorological Parameters}

\subsubsection{Precipitation}

The relationship between dust storm frequency and precipitation is presented in Figure 4 , while the simple regression results are shown in Table 2. There are clear negative correlations between annual dust storm frequency and precipitation $(\mathrm{R}=-0.71, \mathrm{P}=$ 0.001). However, there is no obvious correlation between monthly dust storm frequency and precipitation given the unremarkable correlation coefficient $(\mathrm{R}=-0.082, \mathrm{P}=$ 0.540) (Table 2).

\subsubsection{Wind Speed}

Wind is the dynamic force of dust storm formation (Bagnold, 1941). The relationship between annual wind speed and dust storm frequency is analyzed in the period of 1983-2013. A positive correlation can be found between them with high statistical significance $(\mathrm{R}=0.92, \mathrm{P}=0.001)$. Monthly correlations between wind speed and dust storms are also analyzed. Results show that there is a significant positive correlation between wind speed and dust storm frequency with $\mathrm{R}=0.91, \mathrm{P}=0.001$ at the $95 \%$ confidence level (Table 2). As a dynamic force of dust storm formation, the wind conditions play an essential role in determining the frequency and intensity of dust storms. Wind conditions can be: large-scale or synoptic wind systems and smaller patterns known as mesoscale wind systems. Synoptic wind systems cover great distances. During the spring, a low atmospheric pressure system prevails within the study area, while the Siberian and Mongolian high pressure systems move into the study area from the north and northeast directions. This synoptic situation causes strong winds, and hence dust storms frequency in the study area is increased. Mesoscale systems are smaller weather systems that cause local wind systems. The study area is located between the Tangri Mountain with an average altitude of $5000 \mathrm{~m}$ and the Taklimakan Desert. The peaks of this mountain are covered with snow and ice. Due to the temperature difference between the mountain and desert, the local winds, such as down-slope winds, gap winds and convection, always cause frequent dust storms in the study area. It can be clearly seen from Table 1 and Figure 3 that dust storm frequency is decreased in the summer and autumn months although strong wind conditions still exist, e.g., the average wind speeds in June and July were $6.2 \mathrm{~m} / \mathrm{s}$ and $4.1 \mathrm{~m} / \mathrm{s}$, respectively (Table 1).

\subsubsection{Temperature}

The relationship between temperature and dust storms is not simply linear. For example, higher temperatures would be helpful for vegetation growth. As a mechanical barrier, plants can effectively decrease the velocity of surface friction wind [18]-[20]. Moreover, the greater vegetation coverage in summer and autumn increases the surface roughness; hence, the frequency of dust storms is decreased in this period. In this case, increased temperature can effectively reduce dust storms. However, higher temperatures during conditions with lower precipitation will induce drought, enhance surface dust particle sources and thereby accelerate dust storm formation. In this study, a certain 

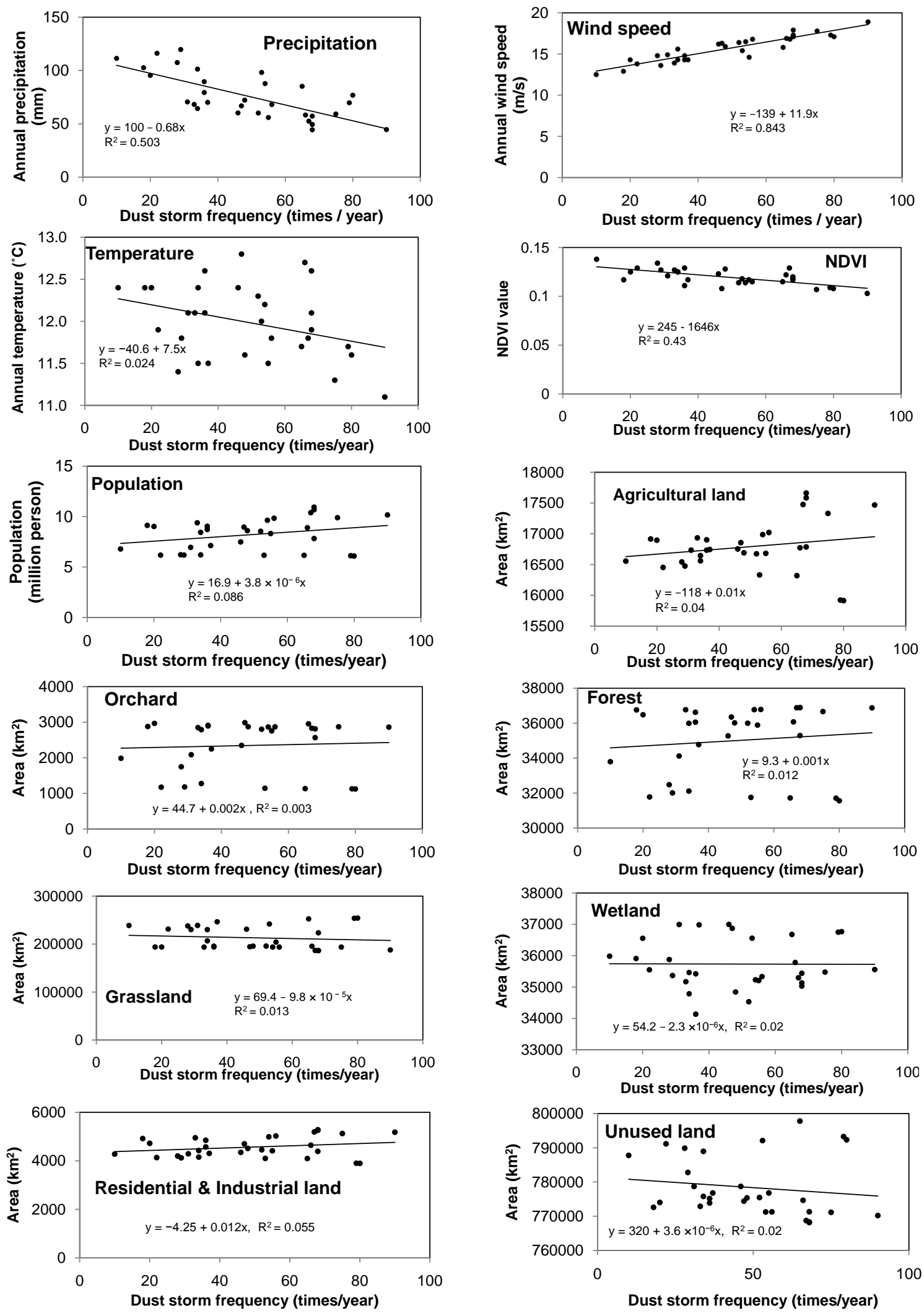

Figure 4. Linear regression between annual dust storm frequency with annual meteorological factors, LUCC, NDVI (representative values for each year) and population (1983-2013). 
correlation was identified between annual temperature and dust storm frequency with an unremarkable correlation coefficient $(\mathrm{R}=0.16, \mathrm{P}=0.402)$ over a longer period ( Table 2).

Overall, precipitation, wind speed and temperature are three meteorological factors that can impact dust storm formation as well as the frequency and intensity of dust storms. Based on the linear regression between dust storm frequency and the three meteorological factors, the monthly dust storm frequency is positively correlated with wind speed and is not significantly correlated with precipitation and temperature. The annual dust storm frequency was positively correlated with wind speed and negatively correlated with precipitation with a remarkable statistical significance.

\subsection{Land Surface Cover and Dust Storm Occurrence}

The occurrence of dust storms is not only the result of natural factors but also the result of human activities, including overgrazing and deforestation, which reduce vegetation coverage [21]-[24]. Therefore, the variation trends of dust storms are analyzed together with other indicators of land use/cover changes using a long-term observation data series. The vast majority of the landscape in this area is covered by barren deserts; the Gobi Desert and scarce grasslands are shown in Figure 1. The historical LUCC data from whole southern Xinjiang region (Figure 1), with the total area of 1,100,000 $\mathrm{km}^{2}$, were considered in analyzing the relationships between dust storm frequency and the LUCC. Among the seven types of land, grassland, wetland and unused land were reduced while the other four types of land were expanded from 1983 to 2013. During the entire study period (1983-2013), an area of $24,189 \mathrm{~km}^{2}$ of unused land and $67,750 \mathrm{~km}^{2}$ of grassland disappeared (Figure 5). It can be assumed that the grassland and unused land were changed into other types of land uses. Regarding the reduction of the wetland area, previous research indicated that, due to rapid population growth in southern Xinjiang, the demand for water resources is growing rapidly [5]. As a result, some natural lakes and river are shrinking or have been dried up. This could be a reason for the reduction of the wetland area. No significant correlation can be found between particular LUCC and dust storm frequency. Only the NDVI is negatively correlated with dust storm frequency $\left(R^{2}=0.43\right)$. In the southern Xinjiang region, in addition to the Gobi and mobile deserts, there are vast areas of transit zones between the oasis and the

Table 2. Simple regression between dust storm frequency and meteorological factors.

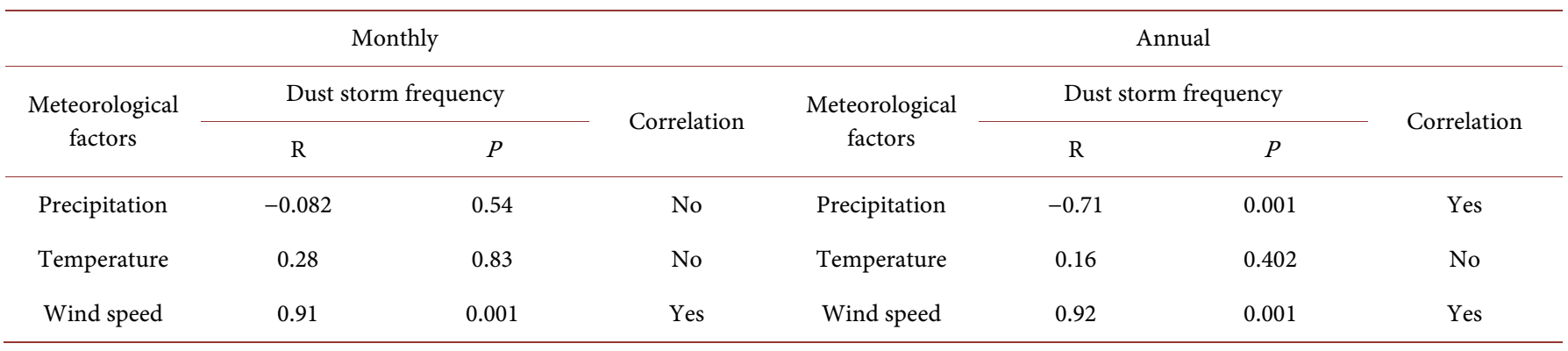

Note: $\mathrm{R}$ is correlation coefficient; $\mathrm{P}$ is statistical significance. 

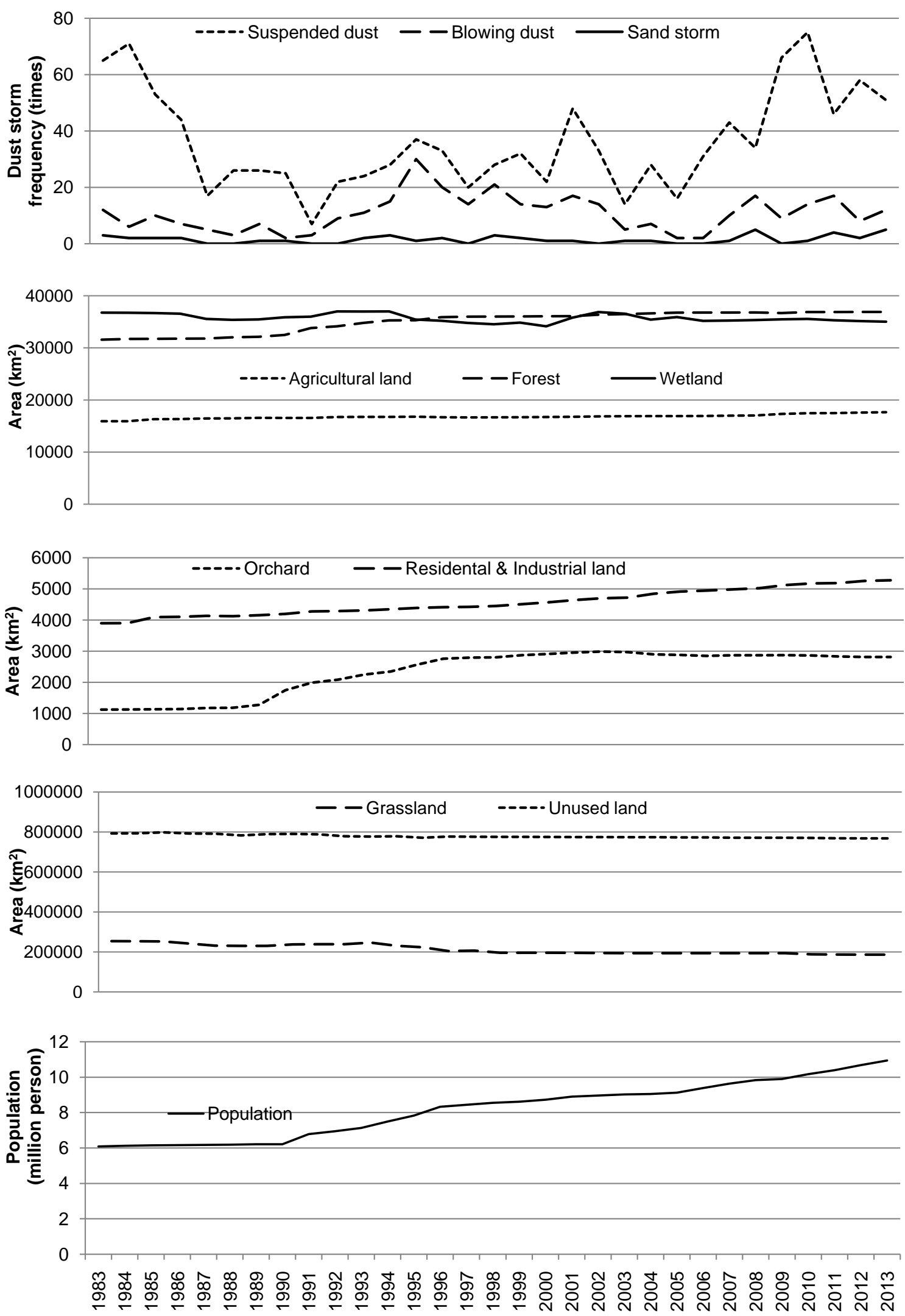

Figure 5. Relationship between LUCC, population and dust storm frequency (1983-2013). 
desert, which have been described as an "ecological fragile region". These areas play an essential role in protecting the oasis from desertification and dust storm impacts, but at present, they have been nearly fully utilized for grazing, planting and urban construction [12]. Rapid desertification occurred in the agricultural and pastoral areas in the southern Xinjiang region. Figure 5 shows that from 1983 to 2013, grassland cover was significantly reduced, and the change was more dramatic from 1993 to 1997. The agricultural land, orchard, forest and residential \& industrial land were slightly increased from 1983 to 2013. The loss of grassland cover in this region was observed since 1985. During the period, the population also increased, which may be linked to the China Central Government's new western development strategy. Accordingly, large numbers of immigrants have arrived in southern Xinjiang since the late 1990s. The increase of population forces people to enlarge cultivated areas. The dominant human activities that may influence dust emissions include grazing, planting, cutting shrubs and deforestation which would result in changes of land use types.

Furthermore, in order to examine the relationship between vegetation cover changes and dust storm frequency, the value of NDVI for each year during the period of 19832013 was obtained by using ERDAS image software. The obtained NDVI values for the different landscapes were very different. For example, the NDVI value of the mobile desert is $0.05-0.06$, the Gobi Desert is $0.07-0.09$, the fixed dunes are $0.12-0.17$, the forest is $0.55-0.70$, the grassland is $0.60-0.75$ and the farmland is $0.65-0.83$. Note that NDVI, in principle, ranges from -1 to +1 , with values of 0.5 indicating dense vegetation and values $<0$ indicating no vegetation [19]. A simple time-series analysis was conducted to identify the relationship between vegetation cover change and dust storm frequency, as presented in Figure 4. The inter-annual changes in the LUCC in the entire southern Xinjiang region during the last 31 years are presented in Figure 5. Due to the presence of vast areas of mobile desert, fixed dunes and barren land, the selected monthly mean NDVI value of the entire area shows lower value $(0.108-0.138)$. Although the fluctuations of the NDVI value are not remarkable, there was a decreasing trend after 1991, suggesting that vegetation cover decreased in this period. For example, during the period of 1987-1992, the dust storm frequency decreased (10 - 34 times/ year); coincidentally in this period, the NDVI value was higher $(0.129-0.138)$. A negative correlation was obtained for the entire study period $\left(\mathrm{R}=-0.67, \mathrm{P}=0.001\right.$ and $\mathrm{R}^{2}=$ $0.43)$.

During the entire study period, from 1983 to 2013, the forest area increased from $31,564 \mathrm{~km}^{2}$ to $36,895 \mathrm{~km}^{2}$, orchard increased from $1124 \mathrm{~km}^{2}$ to $2814 \mathrm{~km}^{2}$ and agricultural land increased from $15,915 \mathrm{~km}^{2}$ to $17,662 \mathrm{~km}^{2}$. The total increase of these land areas was $8768 \mathrm{~km}^{2}$ during this period. However, during this period, grassland was decreased from $254,197 \mathrm{~km}^{2}$ to $186,447 \mathrm{~km}^{2}$, i.e., by $67,750 \mathrm{~km}^{2}$ (Figure 5). The decrease in the grassland area was much larger than the total increase in the area of the three types (forest, orchard and agricultural land) above. Therefore, the average NDVI value of the entire southern Xinjiang region shows a decreasing trend in this period.

Thus, it can be assumed that the economic activities in this area can enhance dust 
particle emission, which can create a dust storm hazard if the wind and other weather factors are conducive. Some of the activities that are relevant for this study area are listed as follows:

\section{1) Excessive Cultivation}

Due to limited natural resources, such as water scarcity, marginal soil, the yield of arable land in the southern Xinjiang region is generally low and unstable [5]. The increase in population forces people to enlarge cultivated areas. For instance, the population in southern Xinjiang increased from 6,022,160 in 1983 to 10,937,867 in 2013 [25]. In the same period, the agricultural land increased from $15,915 \mathrm{~km}^{2}$ to $19,661 \mathrm{~km}^{2}$. New land was cultivated at the expense of the shelter-forest and vegetation. Without the protection of the shelter-forest and the vegetation against wind erosion, this area became more and more vulnerable, and the fertility of the arable land declined, which made crop production unstable and reduced year after year until finally people were forced to abandon it and cultivate new land [4]. The massive discarded land was gradually desertified and became a source of sand and dust particles.

\section{2) Overgrazing}

Most of grassland in southern Xinjiang is located in an arid and semi-arid belt in which the ecological environment is harsh and the ecological grassland system has a low self-resilient capacity [26]. A sharp increase of population would result in massive cultivation that perhaps make the grassland area declined (Figure 5). Meanwhile, corresponding to the population increase, the demand of livestock should also be increasing, which would lead to overgrazing. During the period from 1983 to 2013, the area of grassland was reduced by $26.7 \%$. Chen et al. (2002) reported that the over-loading rate of livestock in the grassland in the dust storm area in China is $50 \%-200 \%$; some areas even reach $300 \%$ [27].

\section{3) Deforestation}

The rural area of southern Xinjiang generally lacks energy, especially fuel for daily use. The rural inhabitants depend mainly on the uprooting and lumbering of natural vegetation and the excrement of livestock for fuel [5]. A sharp increase of population intensified the shortage of fuel, thereby making the situation worse. From 1983 to 2013, although the total area of forest and orchard were increased by $1660 \mathrm{~km}^{2}$ and $5331 \mathrm{~km}^{2}$, respectively, most of these newly expanded forests and orchards were merely planted on land that was originally cultivated or grassland. The natural forest that existed between the desert and oasis, which played an essential role in protecting the oasis from desertification and dust storm impacts, was cultivated or changed to industrial land and other types of land [28]. The natural poplar forest in the lower reaches of the Tarim River was reported to have reduced from $5200 \mathrm{~km}^{2}$ in 1958 to $2800 \mathrm{~km}^{2}$ in 2013 . These processes intensified the desertification in this area, which would enhance the dust storms.

\section{4) Unreasonable Utilization of Limited Water Resources}

In southern Xinjiang, precipitation is very low with an annual precipitation of 50 $\mathrm{mm}$, hence water sources are limited. A large scale of newly cultivated land in the arid 
area requires a huge amount of water for irrigation. Because of the lack of water for irrigation, $92.87 \mathrm{~km}^{2}$ of arable land were discarded and desertified in the Tarim River basin from 1970 to 2010 [29]. Figure 5 showed that the wetland area in southern Xinjiang decreased from $36,767 \mathrm{~km}^{2}$ in 1983 to $30,032 \mathrm{~km}^{2}$ in 2013 . On the one hand, increasing consumption of water resulted in a groundwater level decline, which made vegetation die and further made land desertified because of the loss of protection from vegetation. On the other hand, unreasonable irrigation methods, namely irrigation without drainage and over-irrigation, led to the salinization of soil [30]. These factors together intensified the dust storm events in the study area.

\subsection{Multivariate Association between Dust Storms, Meteorological Factors and the LUCC}

The PCA was applied to further reveal the association between dust storm frequency, meteorological factors and the LUCC. The dataset of 13 variables, including dust storm frequency observed at Bugur County, the seven types of land of the southern Xinjiang region, three meteorological factors (precipitation, wind speed and temperature) measured at Bugur County, the NDVI value (the representative monthly mean value in August/July of a year) of each year for the southern Xinjiang region as described above and population data of each year from 1983 to 2013 for the southern Xinjiang region were analyzed by using PCA. For the wind speed data, the average wind speed of March, April and May in each year was calculated from the daily wind speed of the months because of the high dust storm frequencies during this period, and this average value of wind speed in this period was used to represent the wind speed in the respective year, which was used for PCA. Note that the standardized value, which has a mean of 0 and standard deviation of 1 , of each variable was used for the analysis. The results of the PCA are presented in Table 3.

The PCA with a Varimax rotation produced three principal components (PC), which can explain $85.3 \%$ of the total variance of the original dataset, as illustrated in Table 3 . Component 1 , which explains $55.5 \%$ of the variance, contains information on population, land use types of agricultural land, orchard, forest, and residential \& industrial land areas with positive loadings; and precipitation, grassland, wetland, and unused land areas with negative loadings. The agricultural land, forest, orchard and residential \& industrial lands were expanded and positively correlated with population growth. In the meantime, during this process, grassland, wetland and unused land were converted into other types of land, so that they were negatively correlated with population growth and other types of land. Component 2, which explains $22.1 \%$ of the total variance, has high positive loadings of dust storm frequency and wind speed, and has negative loadings of precipitation and the NDVI value. Precipitation is needed for vegetation growth, and increasing vegetation coverage can reduce dust storms. Therefore, as a direct reflection of the vegetation coverage, the NDVI value is positively correlated with precipitation and negatively correlated with dust storm frequency. Moreover, as a dynamic force of dust storms, the wind speed is positively correlated with dust storm frequency 
Table 3. Multivariate association between dust storm, meteorological factors and LUCC.

\begin{tabular}{cccc}
\hline Variables & \multicolumn{3}{c}{ Principal components } \\
\cline { 2 - 4 } & 1 & 2 & 3 \\
\hline Dust storm frequency & 0.069 & 0.925 & -0.244 \\
Precipitation & -0.471 & -0.723 & -0.069 \\
Temperature & 0.282 & -0.291 & 0.779 \\
Wind speed & 0.167 & 0.900 & -0.183 \\
Population & 0.953 & 0.246 & 0.036 \\
NDVI & -0.025 & -0.825 & -0.112 \\
Agricultural land area & 0.877 & 0.170 & -0.084 \\
Orchard area & 0.925 & 0.077 & 0.235 \\
Forest area & 0.952 & 0.127 & 0.197 \\
Grassland area & -0.957 & -0.039 & 0.006 \\
Wetland area & -0.629 & 0.259 & 0.508 \\
Communality percentages of variance (\%) & 55.5 & 0.194 & -0.030 \\
Pesidential \& Industrial land area & 0.921 & -0.155 & -0.120 \\
Unused land area & -0.938 & 22.1 & 7.7 \\
Percentages of variance (\%) & 55.5 & 77.6 & 85.3 \\
\hline
\end{tabular}

Note: Extraction method: Principal Component Analysis. Rotation method: Varimax with Kaiser Normalization.

with a high loading. The third component explains $7.7 \%$ of the total variance and has high loadings of temperature and wetland, which perhaps shows the association between these two variables.

Thus, dust storm events appeared to be the result of the combined effects of and land surface factors. Besides the natural meteorological factors, the land use factors would be linked to human activities, which affect the dynamics of dust storms via changing vegetation coverage and hence affecting the dust emissions. Human development activities, such as excessive cultivation, over grazing, deforestation and unreasonable utilization of limited water resources have reduced the vegetation coverage as discussed above. It was expected that the NDVI would show more significance in component 1 where most of the human variables appeared. The linear regression analysis also showed this relationship.

\section{Conclusion}

Dust storm is closely related to meteorological conditions and land surface features. The aforementioned results and discussion suggest that many drivers may affect the occurrence of sand-dust storm events. Precipitation, wind speed and temperature are three meteorological drivers that influence the frequency of dust storm events. Wind speed is the major dynamic force of dust storm formation. A significant correlation exists between both monthly and annual dust storm frequency and wind speed. Precipita- 
tion enhances vegetation growth in this arid area. Therefore, the annual precipitation is negatively correlated with dust storm frequency. However, the relationship between monthly precipitation and monthly dust storm frequency is not statistically significant. Temperature may also affect the occurrence of dust events. However, there was no significant correlation found between dust storm frequency and temperature in this study. This result may be because the relationship is not straightforward and involves many variables. Vegetation is the mean surface feature capable reducing or eliminating the contact between soil and the atmosphere. Both human activities and environmental factors are responsible for changes in vegetation cover. The increase in vegetation would prevent an outbreak of dust storms. The linear regression between the NDVI and dust storm frequency in the study area shows a negative slope. Population growth can also have an impact on dust storm formation via changing the land surface features. With the rapid population growth, vast areas of grassland, forest land and other noncultivated land were replaced by residential area or arable land. During the spring periods, this arable land would have no vegetation coverage; hence it becomes a potential source of dust particles. The multivariate analysis further confirmed the association between dust storm frequency and meteorological factors and the NDVI. High loadings of dust storm frequency, wind speed, precipitation and NDVI on a PC indicate that the increased precipitation and NDVI will decrease dust storm frequency, and increased wind speed will increase dust storm frequency.

\section{Acknowledgements}

This study was supported by the National Natural Science Foundation of China (No. 41471098) and the International Science and Technology Cooperation Program of China (2010DFA92720). The authors would like to thank the staff of the Environmental Monitoring Department of Xinjiang Uyghur Autonomous Region and the Meteorological Department of Bugur County for providing ambient air monitoring and meteorological data.

\section{References}

[1] Zhang, B.L., Atsushi, T. and Mitsuru, T. (2008) Contributions of Sandy Lands and Stony Deserts to Long-Distance Dust Emission in China and Mongolia during 2000-2006. Global and Planetary Change, 60, 487-504. http://dx.doi.org/10.1016/j.gloplacha.2007.06.001

[2] Nickling, W.G. and Brazel, A.J. (1984) Temporal and Spatial Characteristics of Arizona Dust Storms (1965-1980). International Journal of Climatology, 4, 645-660. http://dx.doi.org/10.1002/joc.3370040608

[3] Gillette, D.A. (1981) Production of Dust That May Be Carried Great Distances. Special Papers-Geological Society of America, 196, 11-26. http://dx.doi.org/10.1130/spe186-p11

[4] Sun, D.F., Richard, D. and Li, B.G. (2006) Agricultural Causes of Desertification Risk in Minqin, China. Journal of Environmental Management, 79, 348-356. http://dx.doi.org/10.1016/j.jenvman.2005.08.004

[5] Lei, J. and Zhang, X.L. (2005) Structural Adjustment of Oasis Agriculture in Xinjiang. Chinese Journal of Population, Resources and Environment, 3, 58-63. (In Chinese) 
[6] Gao, W.D., Yuan, Y.J., Liu, Z.H. and Wei, W.S. (2008) Status of Dust Sources and Aerosol Formatting Condition Analysis in Xinjiang. Journal of Desert Research, 28, 968-973. (In Chinese)

[7] Xia, C.D. and Yang, G.S. (1994) Some Problems of the Northwest Sand-Dust Storms in China. Bulletin of the Chinese Academy of Sciences, 4, 346-350. (In Chinese)

[8] Aili, A. and Kim Oanh, N.T. (2015) Effects of Dust Storm on Public Health in Desert Fringe Area: Case Study of Northeast Edge of Taklimakan Desert. Atmospheric Pollution Research, 6, 805-814. http://dx.doi.org/10.5094/APR.2015.089

[9] Cheng, H.X., Hu, L.Q. and Lin, Y.J. (2014) Temporal and Spatial Distribution Characteristics of Hot and Cold Spots of Sandstorm in Xinjiang in Recent 50 Years. Journal of Arid Land Resources and Environment, 28, 100-104. (In Chinese)

[10] Liu, M.Z. and Wei, W.S. (2005) Effects of Climate Change on the Occurrence of Dust Storms in Southern Xinjiang since Recent 60 Years. Arid Land Geography, 28, 479-483. (In Chinese)

[11] Aili, A. (2010) Assessment of the Impacts of the Sand-Dust Storm on Oasis Agriculture in Arid Area: A Case Study of Bugur County, Northwest China. Master's Thesis, No. NR-10 -12, Asian Institute of Technology, Bangkok.

[12] Lai, X.Q., Qin, L. and Zhang, F.H. (2002) The Eco-Agricultural Construction of Oases and Its Sustainable Development in Xinjiang. Chinese Journal of Eco-Agriculture, 10, 129-130.

[13] Liu, X., Yin, Z.Y., Zhang, X. and Yang, X. (2004) Analyses of the Spring Dust Storm Frequency of Northern China in Relation to Antecedent and Concurrent Wind, Precipitation, Vegetation, and Soil Moisture Conditions. Journal of Geophysics, 4, 105-109. http://dx.doi.org/10.1029/2004jd004615

[14] Chen, Y.N., Xu, C.C., Hao, X.M., Li, W.H., Chen, Y.P., Zhu, C.G. and Ye, Z.X. (2009) Fifty Year Climate Change and Its Effect on Annual Runoff in the Tarim River Basin, China. Quaternary International, 29, 1-9. http://dx.doi.org/10.1016/j.quaint.2008.07.019

[15] AQSIQ (Administration of Quality Supervision, Inspection and Quarantine) and NSC (National Standards Committee) of People's Republic of China (2006) Dust Storm Weather Classification Criterion, Standard Code: GBT 20480-2006. China Standard Press, Beijing, 7.

[16] Qian, W.H., Quan, L.S. and Shi, S.Y. (2002) Variations of the Dust Storm in China and Its Climatic Control. Journal of Climate, 15, 76-80. http://dx.doi.org/10.1175/1520-0442(2002)015<1216:VOTDSI >2.0.CO;2

[17] Zaiontz, C. (2015) Real Statistics Using Excel. www.real-statistics.com

[18] Rice, M.A., Willetts, B.B. and McEwan, I.K. (1996) Wind Erosion of Crusted Soil Sediments. Earth Surface Processes and Landforms, 21, 279-293. http://dx.doi.org/10.1002/(SICI)1096-9837(199603)21:3<279::AID-ESP633>3.0.CO;2-A

[19] Xu, X.K., Levy, J.K., Lin, Z.H. and Chen, H. (2006) An Investigation of Sand-Dust Storm Events and Land Surface Characteristics in China Using NOAA NDVI Data. Global and Planetary Change, 52, 182-196. http://dx.doi.org/10.1016/j.gloplacha.2006.02.009

[20] Zhou, X.J., Xu, X.D., Yan, P., Weng, Y.H. and Wang, J.L. (2002) Dynamic Characteristics of Spring Sandstorms in 2000. Science in China Series D, 45, 921-930. http://dx.doi.org/10.1360/02yd9091

[21] Shi, Y.L., Wang, R.S., Fan, L.Y., Li, J.S. and Ye, D.F. (2010) Analysis of Land Use-Change and Its Demographic Factors in the Original-stream Watershold of Tarim River Baed on GIS and Stststics. Procedia Environmental Science, 2, 175-184. http://dx.doi.org/10.1016/j.proenv.2010.10.021 
[22] Sruthi, S. and Mohammed, A. (2015) Agricultural Drought Analysis Using the NDVI and Land Surface Temperature Data: a Case Study of Raichur District. Aquatic Procedia, 4, 1258-1264. http://dx.doi.org/10.1016/j.aqpro.2015.02.164

[23] UNEP (1997) Report of the UNEP/RIVM/PE Workshop on Global and Regional Modeling of Food Production and Land Use and the Long-term Impact of Degradation of Land and Water Resources.

[24] Bouma, J. (2002) Land Quality Indicators of Sustainable Land Management across Scales. Agriculture, Ecosystem and Environment, 88, 129-136. http://dx.doi.org/10.1016/S0167-8809(01)00248-1

[25] Xinjiang Statistical Yearbook (2014) Statistics Press, Beijing.

[26] Ye, D.Z., Chou, J.F. and Liu, J.Y. (2000) On the Causes of Sand-Dust Storms in North China and Counter-Measures. Acta Geographica Sinica, 55, 513-520. (In Chinese)

[27] Chen, J., Chen, J.Z., Tan, M.Z. and Gong, Z.T. (2002) Soil Degradation: A Global Problem Endangering Sustainable Development. Journal of Geographical Science, 12, 243-252. http://dx.doi.org/10.1007/BF02837480

[28] Chen, W.L., Hua, P., Guan, C.H., Liu, Y.H. and Li, W.D. (2012) Historical Development of Populus Ephratica in Upper Stream of Tarim River and Its Causes. Journal of Anhui Agricultural Science, 40, 292-294. (In Chinese)

[29] Li, C.Z. (2012) Study on the Desertification Monitoring and Early-Warning in Xinjiang. Doctoral Dissertation of Xinjiang University, Xinjiang, 35-46. (In Chinese)

[30] Guo, L. (2005) Population Distribution and Its Changes in Xinjiang since Founding of People's Republic of China. Northwest Population, 103, 20-24. (In Chinese)

\section{Submit or recommend next manuscript to SCIRP and we will provide best service for you:}

Accepting pre-submission inquiries through Email, Facebook, LinkedIn, Twitter, etc. A wide selection of journals (inclusive of 9 subjects, more than 200 journals)

Providing 24-hour high-quality service

User-friendly online submission system

Fair and swift peer-review system

Efficient typesetting and proofreading procedure

Display of the result of downloads and visits, as well as the number of cited articles

Maximum dissemination of your research work

Submit your manuscript at: http://papersubmission.scirp.org/

Or contact ojap@scirp.org 